\title{
Differences in the reaction of hyperlipidemia on different endothelial progenitor cells based on sex
}

\author{
XIAOQING ZHUO ${ }^{1,2^{*}}$, HAORAN BU ${ }^{3 *}, \mathrm{KE} \mathrm{HU}^{4}$, ZHIHUA SI $^{5}$, LIMING CHEN $^{1,6}$, \\ YONG CHEN $^{3}$, LE YANG $^{1,6}$, YUFAN JIANG ${ }^{1,6}$, YIXIN XU ${ }^{1,6}$, PENG ZHAO $^{1,6}$, XIAOCHUN MA $^{7}$, \\ SHUFEI TAO ${ }^{8}$, QINGYI ZHU ${ }^{9}$, LIANQUN CUI ${ }^{1,6}$, HAIHUI SUN ${ }^{1,6}$ and YUQI CUI ${ }^{1,6}$
}

\begin{abstract}
${ }^{1}$ Department of Cardiology, Shandong Provincial Hospital, Cheeloo College of Medicine, Shandong University, Jinan, Shandong 250021; ${ }^{2}$ Department of Cardiology, Shandong Second Provincial General Hospital, Shandong University, Jinan, Shandong 250118; ${ }^{3}$ Department of Emergency, Shandong Provincial Hospital Affiliated to Shandong First Medical University, Jinan, Shandong 250021; ${ }^{4}$ Department of Emergency; ${ }^{5}$ Department of Neurology, Qianfoshan Hospital, Shandong First Medical University, Jinan, Shandong 250014; ${ }^{6}$ Department of Cardiology; ${ }^{7}$ Department of Cardiovascular Surgery, Shandong Provincial Hospital Affiliated to Shandong First Medical University, Jinan, Shandong 250021, P.R. China;

${ }^{8}$ Ross University School of Medicine, Barbados 60515, Barbados; ${ }^{9}$ Department of Cardiovascular Medicine, Second Xiangya Hospital, Central South University, Changsha, Hunan 410008, P.R. China
\end{abstract}

Received March 9, 2021; Accepted May 21,2021

DOI: $10.3892 /$ br.2021.1440

\begin{abstract}
The sex of a patient can affect the outcomes of several cardiovascular diseases, and men generally tend to experience earlier episodes of cardiovascular diseases compared with women. The progression of atherosclerosis during hyperlipidemia can be induced by reactive oxygen species (ROS) and oxidized-low-density lipoprotein (ox-LDL). By contrast, bone marrow (BM)-derived endothelial progenitor cells (EPCs) have been reported to serve a protective role against atherosclerosis. The aim of the present was to compare the effects of sex under conditions of hyperlipidemia on different populations of EPCs, and to identify the potential underlying mechanisms. EPC numbers and ROS levels in the blood and $\mathrm{BM}$ were measured using fluorescence activated cell sorting in male and female LDL receptor knock-out C57BL/6 mice maintained on a high-fat diet for 6 months, and in male and female wild type C57BL/6 mice following ox-LDL injection for 3 days. Female hyperlipidemic mice exhibited lower levels of plasma lipids, atherosclerotic plaque formation, intracellular EPC ROS formation and inflammatory cytokine
\end{abstract}

Correspondence to: Dr Yuqi Cui or Dr Haihui Sun, Department of Cardiology, Shandong Provincial Hospital Affiliated to Shandong First Medical University, 324 Jing 5 Road, Building 3, Jinan, Shandong 250021, P.R. China

E-mail: cuiyu@health.missouri.edu

E-mail: sunhaihui569@sina.com

*Contributed equally

Key words: sex, endothelial progenitor cells, reactive oxygen species, oxidized low-density lipoprotein, hyperlipidemia levels. Furthermore, BM CD34+/ fetal liver kinase-1 (Flk-1+), $\mathrm{CD} 34^{+} / \mathrm{CD} 133^{+}$and stem cell antigen- $1^{+} / \mathrm{Flk}-1^{+}$, as well as all circulating EPCs, were maintained at higher levels in female hyperlipidemic mice. In addition, similar changes with regards to $\mathrm{BM} \mathrm{CD} 34^{+} / \mathrm{Flk}^{+} 1^{+}, \mathrm{CD} 34^{+} / \mathrm{CD} 133^{+}, \mathrm{c}-\mathrm{Kit}^{+} / \mathrm{CD} 31^{+}$and circulating $\mathrm{CD} 34^{+} / \mathrm{Flk1}^{+}$and $\mathrm{CD} 34^{+} / \mathrm{CD} 133^{+}$EPCs were observed in female mice following ox-LDL treatment. These sustained higher levels of BM and circulating EPCs in female mice with hyperlipidemia may be associated with reduced levels of ox-LDL as a result of reduced intracellular ROS formation in EPCs and decreased inflammatory cytokine production.

\section{Introduction}

Differences in the clinicopathological characteristics between men and women can be observed in a variety of diseases, including cardiovascular diseases (1-3). Women of reproductive age tend to be at lower risk of atherosclerosis, myocardial infarction and coronary artery disease (CAD) compared with men in the same age bracket and menopausal women (1). However, the mechanisms underlying these difference remain unknown.

Endothelial injury or dysfunction is considered to be a leading factor underlying the progression of atherosclerosis and CAD (4). Endothelial progenitor cells (EPCs) serve a key role in vascular re-endothelialization and angiogenesis, where they can suppress neointima formation after vascular injury (4). However, the effects of hyperlipidemia on the population profile of EPCs in different sexes and the related mechanisms remain poorly understood.

Oxidized-low-density lipoprotein (ox-LDL) has been reported to be a pivotal element in the hyperlipidemic status, where it has been previously observed to contribute to atherosclerotic plaque formation (5). Patients diagnosed with stable cardiovascular disease and acute coronary syndrome tend to 
exhibit higher levels of ox-LDL in the serum (6). It was also previously suggested that native LDL can be continuously converted to ox-LDL in the blood (7). Therefore, the levels of native LDL are closely associated with the levels of ox-LDL in vivo (7). Ox-LDL can inhibit the proliferation and differentiation of EPCs, thereby suppressing EPC migration, adhesion and vasculogenesis in vitro, and neovascularization after ischemia in vivo (8-10). In addition, a previous study suggested that treating wild type (WT) mice with human ox-LDL confers comparable effects as that of hyperlipidemia on EPCs in LDL receptor knock out $\left(\mathrm{LDLR}^{-/}\right)$mice in vivo (11). However, the concentration of ox-LDL in serum differs between men and women (12). In addition, EPC numbers have also been reported to be higher in women of reproductive age compared with those in age-matched men and postmenopausal women $(13,14)$. These previous observations suggest that EPC numbers may also differ between men and women with hyperlipidemia due to the differences in concentrations of ox-LDL and native LDL between the sexes.

Oxidative stress as a result of reactive oxygen species (ROS) production is an important mediator of atherosclerosis (15). It has been reported that ROS can be induced by elevated ox-LDL levels and a hyperlipidemic status $(11,16)$. A previous study also showed that ROS can facilitate the conversion of native LDL to ox-LDL in WT mice in circulation (7). ROS levels have been demonstrated to be significantly higher in male rat cardiomyocytes, male human serum and vascular cells compared with those in women (17-19). Furthermore, both experimental and clinical results potentially suggest a more powerful antioxidant capacity in women compared with that in men (20). Proinflammatory cytokines, including TNF- $\alpha$ and IL-1 $\beta$, were previously found to be significantly increased in patients with hyperlipidemia (10) or in WT mice following ox-LDL treatment (21). These cytokines also promote hematopoietic cell development and function (22). Nevertheless, estrogen may act on estrogen receptors on EPCs to suppress the expression of genes related to pro-atherosclerosis, whilst promoting the expression of anti-atherosclerosis genes to downregulate proinflammatory cytokine expression (23).

The present study investigated atherosclerotic plaque formation and the numbers of bone marrow (BM) and circulating EPCs in female hyperlipidemic mice or following ox-LDL treatment. The aim was to explore the effects of hyperlipidemia and ox-LDL on EPCs in different sexes and investigate the underlying mechanisms.

\section{Materials and methods}

Preparation of ox- $L D L$. All human procedures were performed in accordance with the Guidelines of the Human Research Ethics Committee of the Shandong Second Provincial General Hospital Affiliated to Shandong University (Jinan, China). The Human Research Ethics Committee of the Shandong Second Provincial General Hospital Affiliated to Shandong University (Jinan, China) approved the experimental protocols (approval no. XYK20181224). All participants agreed to use their samples for scientific research, and informed consent was obtained. In accordance with the Institutional Review Board under Food and Drug Administration regulations (24), venous blood was collected via puncturing the brachiocephalic vein from 10 healthy male donors aged 21 to 32 years old, after they had provided consent, and the blood was collected in heparinized tubes on ice. Adults with diabetes, hyperlipidemia or other diseases that affect blood lipid levels were excluded. Lipoproteins were isolated from plasma using sequential ultracentrifugation with a Beckman TL-100 tabletop ultracentrifuge (Beckman Coulter, Inc.), which was extracted from blood supernatant by centrifuging at $1,500 \mathrm{x} \mathrm{g}$ for $20 \mathrm{~min}$ at $4^{\circ} \mathrm{C}(25)$. The lipoproteins were treated with $0.3 \mathrm{mM}$ EDTA in $1 \mathrm{X}$ PBS (pH 7.4) overnight at $4^{\circ} \mathrm{C}$ and subsequently sterilized using a $0.22-\mu \mathrm{M}$ filter (MilliporeSigma). The Folin Lowry method was used to calculate the protein concentration in the lipoproteins. After dialysis using $5 \mu \mathrm{M}$ copper sulphate at $4^{\circ} \mathrm{C}$ overnight, ox-LDL was sampled from the native LDL immediately, as previously described (26). Thiobarbituric acid reactive substances (TBARS; Sigma-Aldrich; Merck KGaA) were used to monitor the degree of LDL oxidation and to ensure ox-LDL quality and reproducibility using a microplate reader at a wavelength of $532 \mathrm{~nm}$ (BioTek Instruments, Inc.) (27). Specifically, the TBARS value was maintained at 40-50 nmol malondialdehyde/mg protein. There were no detectable TBARS in the native LDL. All product was then stored at $4^{\circ} \mathrm{C}$ and used within 1 month of preparation.

Animal model. All animal procedures were performed in accordance with the Guidelines of the Animal Care Committee of the Shandong Second Provincial General Hospital Affiliated to Shandong University (Jinan, China). The Animal Care Committee of Shandong Second Provincial General Hospital Affiliated to Shandong University approved the experimental protocols (approval no. XYK20181225). All mice were maintained at room temperature with $40-60 \%$ humidity and a $12 \mathrm{~h}$ light/dark cycle, with ad libitum access to food and water.

A total of 10 randomized, age-matched wild-type (WT) male and female C57BL/6 mice (weight, 20土3 g; age, 4-6 weeks; Jackson Laboratory) were administered $50 \mu \mathrm{g}$ prepared ox-LDL daily via tail vein injections for 3 days, as described previously (7). A total of $1025 \pm 5 \mathrm{~g} \mathrm{LDLR}^{-1-}$ C57BL/6 male and female mice (age, 4-6 weeks) were also obtained from Jackson Laboratory. The genotyping for WT and $\mathrm{LDLR}^{-/}$mice were further confirmed by Southern blots. All mice were fed a normal diet (ND) until 8 weeks of age, after which they were fed a high-fat diet (HFD; 17\% anhydrous milk fat and $0.2 \%$ cholesterol; Harlan Laboratories, Inc.) for 6 months to induce hyperlipidemia. Age-matched male and female WT C57BL/6 mice on an HFD or ND, and LDLR ${ }^{-1}$ male and female mice fed with ND were used as the controls.

After 6 months of HFD treatment, isoflurane was used to induce $(3 \%)$ and maintain $(1.5 \%)$ anesthesia in mice for blood collection (300-500 $\mu \mathrm{l})$ via cardiac puncture. Animals were then immediately euthanized using $\mathrm{CO}_{2}(50-70 \%$ of the chamber volume per min) and death was confirmed by ascertaining cardiac and respiratory arrest or by observing fixed and dilated pupils. Aorta and BM were collected after confirming death of animals.

Lipid profile measurements and atherosclerotic plaque ratio calculation. After 6 months of HFD treatment, blood plasma samples from all mice were collected for lipid profile testing. Plasma (40 $\mu \mathrm{l}$ ) was tested using the Cholestech LDX lipid profile 
cassette (Alere 10-989; Central Infusion Alliance, Inc.) for each test coupled with the Alere Cholestech LDX system (Alere Cholestech). Total cholesterol (TC), triglyceride (TRG), LDL, high density lipoprotein (HDL), non-HDL and the TC/HDL ratio were measured. Mouse aortas were also isolated for the atherosclerotic plaque formation test. Red oil (MilliporeSigma) was used to stain the atherosclerotic plaque at room temperature for $5 \mathrm{~min}$, where the plaque area against the total inner surface of aorta was calculated as previously described (28).

Analysis of EPCs. BM and blood cells were harvested to observe the effects of ox-LDL and hyperlipidemia on the population of blood and BM EPCs in male and female mice. After eliminating red blood cells (RBCs) with RBC lysis buffer (Thermo Fisher Scientific, Inc.), a BD ${ }^{\mathrm{TM}}$ LSRII system (BD Biosciences) was used to perform multicolor analysis for BM and blood EPCs.

An endothelial cell marker combined with a stem cell marker, including CD34 ${ }^{+} /$fetal liver kinase-1 (Flk-1) ${ }^{+}$, Stem cell antigen- 1 (Sca-1) $)^{+} /$Flk-1, c-Kit $/$CD $31^{+}$and $\mathrm{CD} 34^{+} / \mathrm{CD}^{+} 33^{+}$, were used to identify EPCs as previously described (29). Functional EPCs express the endothelial markers Flk-1 and CD31 (29). BM and blood EPCs with a total of 50,000 cells in each sample were carefully analyzed and described (Fig. S1). All cell populations were carefully compensated (each cell population percentile was confirmed further using single antibody staining) and determined using flow cytometry, as previously described (30-36). Flk-1 APC-Cy ${ }^{\text {Tм}} 7$ (cat. no. 561252) antibody was obtained from BD Biosciences and CD34 FITC (cat. no. 11-0341-82) from eBioscience (Thermo Fisher Scientific, Inc.). Sca-1 AF700 (cat. no. 108142), c-Kit-APC (cat. no. 105812), CD31-PE-Cy7 (cat. no. 102418) and CD133-PE (cat. no. 141204) were purchased from BioLegend, Inc. All antibodies were diluted 1:100.

Intracellular ROS detection. Mouse BM and blood were harvested following intravenous injection of $50 \mu \mathrm{g}$ ox-LDL into each mouse for 3 days, as described previously (7). For $\mathrm{LDLR}^{-/}$mice, BM and blood were harvested after 6 months of HFD feeding. RBC lysis buffer was used to remove all RBCs (37). A total of four groups of BM and circulating EPCs were selected for intracellular ROS detection. The mean of the four groups of ROS levels in EPCs were statistically analyzed.

Intracellular ROS generation was measured using FITC conjugated ROS Detection Reagent (cat. no. D399; Invitrogen; Thermo Fisher Scientific, Inc.) as previously described (38). A total of $1 \times 10^{6}$ were incubated at $37^{\circ} \mathrm{C}$ for $10 \mathrm{~min}$ with $5 \mu \mathrm{g} / \mathrm{ml}$ reagent. All labeled cells were washed with PBS twice before suspending in warm PBS. Flow cytometry was used for analysis. BD ${ }^{\mathrm{TM}}$ LSRII (BD Biosciences) at a wavelength of $525 \mathrm{~nm}$ was used to calculate the positively fluorescent cells, as previously described (39).

Measurement of proinflammatory cytokines. Mouse blood samples were harvested after 6 months of HFD or ND treatment. The plasma was obtained from the blood samples after centrifugation at $300 \mathrm{xg}$ for $20 \mathrm{~min}$ at $4^{\circ} \mathrm{C}$. The plasma levels of the proinflammatory cytokines IL-1 $\beta$ (cat. no. 432601) and TNF- $\alpha$ (cat. no. 430904) were evaluated using ELISA kits from BioLegend, Inc. according to the manufacturer's protocols.
Statistical analysis. Data are presented as the mean \pm standard deviation, and analyzed using an unpaired Student's t-test (two-sided) for comparisons between two groups of data, or a two-way ANOVA followed by a Bonferroni post hoc test for comparing the subgroups of data between male and female groups to minimize type I errors as appropriate in GraphPad Prism version 4 (GraphPad Software, Inc.). A two-tailed $\mathrm{P}<0.05$ was considered to indicate a statistically significant difference.

\section{Results}

Lipid levels and atherosclerosis formation are lower in female mice with hyperlipidemia. To study the effects of differences in sex on hyperlipidemia, male and female $\mathrm{LDLR}^{-/}$mice were fed a HFD for 6 months. The TC, TRG, LDL and non-HDL lipoprotein levels, and the TC/HDL ratio were markedly increased in male and female hyperlipidemic $\mathrm{LDLR}^{-/}$mice fed a HFD compared with their respective control groups, confirming that the hyperlipidemic mouse model was successfully established (Table I). Of note, the lipid levels in female hyperlipidemic mice was notably lower compared with that in male hyperlipidemic mice (Table I). In addition, a number of atherosclerotic plaques were present in the aorta of the male hyperlipidemic mice, whereas plaque severity was significantly decreased in the female mouse group $(\mathrm{P}<0.01$; Fig. 1$)$.

BMEPC numbers are increased infemale hyperlipidemic mice. Persistent endothelial cell dysfunction or injury promotes the progression of atherosclerosis and coronary heart disease (4). Therefore, the EPC profiles were examined in the BM of male and female $\mathrm{LDLR}^{-/-}$mice. Hyperlipidemia did not change the BM Sca $-1^{+} / \mathrm{Flk}-1^{+}, \mathrm{c}-\mathrm{Kit}^{+} / \mathrm{CD} 31^{+}$and $\mathrm{CD} 34^{+} / \mathrm{CD} 133$ levels in male mice (Fig. 2B-D), which only exhibited significantly decreased CD34 ${ }^{+} / \mathrm{Flk}^{-}{ }^{+}$levels $(\mathrm{P}<0.05$; Fig. 2A). By contrast, these BM EPC cell populations, except for those expressing $\mathrm{c}-\mathrm{Kit}^{+} / \mathrm{CD} 31^{+}$, were found to be significantly increased in female $\mathrm{LDLR}^{-/-}$mice fed a HFD compared with female $\mathrm{LDLR}^{-/}$mice fed a ND $(\mathrm{P}<0.05)$ and those in male $\mathrm{LDLR}^{-/}$mice fed a HFD $\left(\mathrm{P}<0.05\right.$; Fig. 2A, B and D). The $\mathrm{c}-\mathrm{Kit}^{+} / \mathrm{CD} 31^{+}$cell population in female hyperlipidemic mice was lower compared with that in the male mice, which may be due to the low basal numbers of this cell population in female mice (Fig. 2C).

Blood EPC numbers are high in female hyperlipidemic mice. The circulating EPC numbers were also measured in both $\mathrm{LDLR}^{-1-}$ male and female mice. As shown in Fig. 2E-H, the numbers of circulating EPCs were significantly reduced in both male and female hyperlipidemic mice $(\mathrm{P}<0.05)$ compared with those in their control groups fed a ND. The numbers of blood EPCs, including those expressing CD $34^{+} / \mathrm{Flk}-1^{+}$, Sca $-1^{+} / \mathrm{Flk} 1^{+}, \mathrm{c}-\mathrm{Kit}^{+} / \mathrm{CD} 31^{+}$and $\mathrm{CD} 34^{+} / \mathrm{CD} 133^{+}$, were significantly higher $(\mathrm{P}<0.05)$ in the hyperlipidemic female mice compared with those in the respective male counterparts (Fig. 2E-H).

Lower levels of blood intracellular ROS, plasma TNF- $\alpha$ and IL-6 are observed in female hyperlipidemic mice. To investigate the cause of the differences in EPC numbers 
Table I. Male and female mouse plasma lipid profiles.

\begin{tabular}{|c|c|c|c|c|}
\hline Male, $n=8^{d}$ & $\mathrm{WT}+\mathrm{ND}$ & WT+HFD & $\mathrm{KO}+\mathrm{ND}$ & $\mathrm{KO}+\mathrm{HFD}$ \\
\hline $\mathrm{TC}, \mathrm{mg} \pm \mathrm{dl}$ & $104.7 \pm 3.6$ & $207.3 \pm 34.2^{\mathrm{b}}$ & $231.5 \pm 24.4$ & $1,713 \pm 215.8^{a}$ \\
\hline $\mathrm{HDL}, \mathrm{mg} \pm \mathrm{dl}$ & $56.7 \pm 12.9$ & $102.1 \pm 4.4^{\mathrm{b}}$ & $77 \pm 8.3$ & $74.4 \pm 22.8^{\mathrm{a}}$ \\
\hline $\mathrm{TRG}, \mathrm{mg} \pm \mathrm{dl}$ & $93 \pm 33.3$ & $158 \pm 12.4^{\mathrm{b}}$ & $102.3 \pm 28.7$ & $594.3 \pm 203.5^{\mathrm{a}}$ \\
\hline $\mathrm{LDL}, \mathrm{mg} \pm \mathrm{dl}$ & $5.4 \pm 4.1$ & $12.5 \pm 1.3^{b}$ & $134.8 \pm 19.6$ & $1,586 \pm 90.1^{\mathrm{a}}$ \\
\hline Non-HDL, mg \pm dl & $19.2 \pm 6.7$ & $26.5 \pm 2.1^{\mathrm{b}}$ & $124.5 \pm 68.8$ & $1,711 \pm 85.6^{\mathrm{a}}$ \\
\hline $\mathrm{TC} / \mathrm{HDL}$ & $1.2 \pm 0.1$ & $2 \pm 0.4^{\mathrm{b}}$ & $2.8 \pm 0.4$ & $23.3 \pm 4.9^{\mathrm{a}}$ \\
\hline Female, $n=10^{\mathrm{d}}$ & $\mathrm{WT}+\mathrm{ND}$ & WT+HFD & $\mathrm{KO}+\mathrm{ND}$ & $\mathrm{KO}+\mathrm{HFD}$ \\
\hline $\mathrm{TC}, \mathrm{mg} \pm \mathrm{dl}$ & $101.2 \pm 2.4$ & $185 \pm 24^{b, c}$ & $113.7 \pm 9.3^{c}$ & $775 \pm 94.8^{\mathrm{a}, \mathrm{c}}$ \\
\hline HDL, mg $\pm \mathrm{dl}$ & $68.6 \pm 6.5$ & $76 \pm 10.1^{c}$ & $74.3 \pm 2.5$ & $73 \pm 12.7$ \\
\hline $\mathrm{TRG}, \mathrm{mg} \pm \mathrm{dl}$ & $89.4 \pm 10.2$ & $49.9 \pm 7^{b, c}$ & $61.7 \pm 5.7^{c}$ & $508 \pm 65.1^{\mathrm{a}, \mathrm{c}}$ \\
\hline $\mathrm{LDL}, \mathrm{mg} \pm \mathrm{dl}$ & $4.5 \pm 2.1$ & $10.4 \pm 2.5^{\mathrm{b}}$ & $26.7 \pm 7.2^{c}$ & $596 \pm 101.8^{\mathrm{a}, \mathrm{c}}$ \\
\hline Non-HDL, mg \pm dl & $15.6 \pm 5.4$ & $20.4 \pm 3.4^{b, c}$ & $38.7 \pm 7.4^{c}$ & $697 \pm 89.1^{\mathrm{a}, \mathrm{c}}$ \\
\hline $\mathrm{TC} / \mathrm{HDL}$ & $1.5 \pm 0.4$ & $2.4 \pm 1.1^{\mathrm{b}, \mathrm{c}}$ & $1.5 \pm 0.1^{\mathrm{c}}$ & $10.6 \pm 7.5^{\mathrm{a}, \mathrm{c}}$ \\
\hline
\end{tabular}

${ }^{a} \mathrm{P}<0.001$ vs. respective $\mathrm{KO}+\mathrm{ND}$ group; ${ }^{\mathrm{b}} \mathrm{P}<0.001$ vs. respective $\mathrm{WT}+\mathrm{ND}$ group.; ${ }^{\mathrm{c}} \mathrm{P}<0.001$ vs. the respective male group. ${ }^{\mathrm{d}} \mathrm{Data}$ are presented as the mean \pm standard deviation. HDL, high density lipoprotein; LDL, low density lipoprotein; TRG, triglyceride; TC, total cholesterol; HFD, high fat diet; ND, normal diet; WT+ND, WT C57BL/6 mouse fed a ND for 6 months; WT+HFD, WT C57BL/6 mouse with HFD for 6 months; $\mathrm{KO}+\mathrm{ND}, \mathrm{LDLR}^{-/}$mice with ND for 6 months; KO+HFD, LDL receptor knockout mice fed a HFD for 6 months.
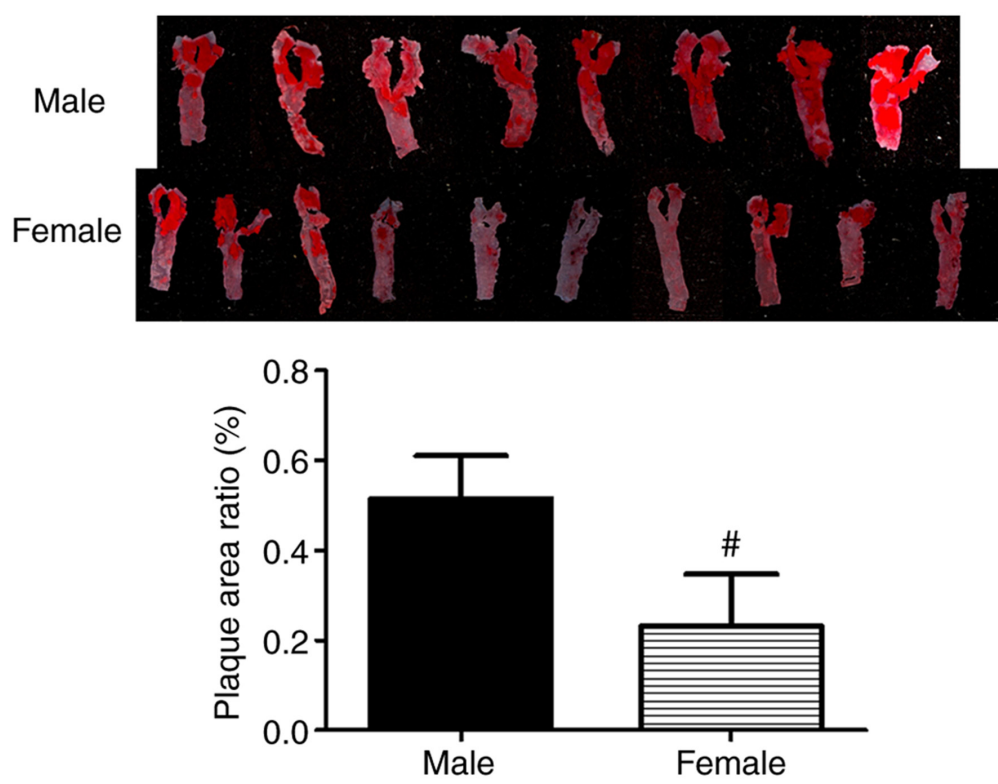

Figure 1. Mouse aortic atherosclerotic formation. Aortas were isolated and stained for atherosclerotic plaque analysis in the male and female hyperlipidemic LDLR $^{-/-}$mice after 6 months of feeding with a high fat diet. A significant amount of atherosclerotic plaque was identified in the hyperlipidemic LDLR ${ }^{-/-}$mice. The levels of atherosclerotic lesions in the female hyperlipidemic LDLR ${ }^{-/-}$mice (lower panel; $\mathrm{n}=10$ ) was significantly reduced compared with the male mice (upper panel; $\mathrm{n}=8$ ). ${ }^{\#} \mathrm{P}<0.001$. $\mathrm{LDLR}^{-/}$, low density lipoprotein receptor knock out.

between male and female mice with hyperlipidemia, the BM and blood EPC intracellular ROS levels were determined. Although there were no intracellular ROS changes in BM EPCs in both male and female mice, a significantly increased ROS level was observed in the blood EPCs of male hyperlipidemic mice compared with that in their corresponding control group fed a ND ( $<<0.01$; Fig. $3 \mathrm{~A}$ and $\mathrm{B})$. The blood EPC intracellular ROS levels were significantly decreased in female LDLR $^{-/}$mice fed with HFD compared with that in the female $\mathrm{LDLR}^{-/}$mice fed with $\mathrm{ND}(\mathrm{P}<0.05)$, and was also significantly lower compared with that in the male $\mathrm{LDLR}^{-/}$ mice fed a HFD ( $\mathrm{P}<0.05$; Fig. 3B).

The plasma inflammatory factor TNF- $\alpha$ and IL-6 levels were next measured in both male and female mice. After feeding the mice with a HFD for 6 months, except for those in the female WT mice, the TNF- $\alpha$ and IL- 6 levels were 
A
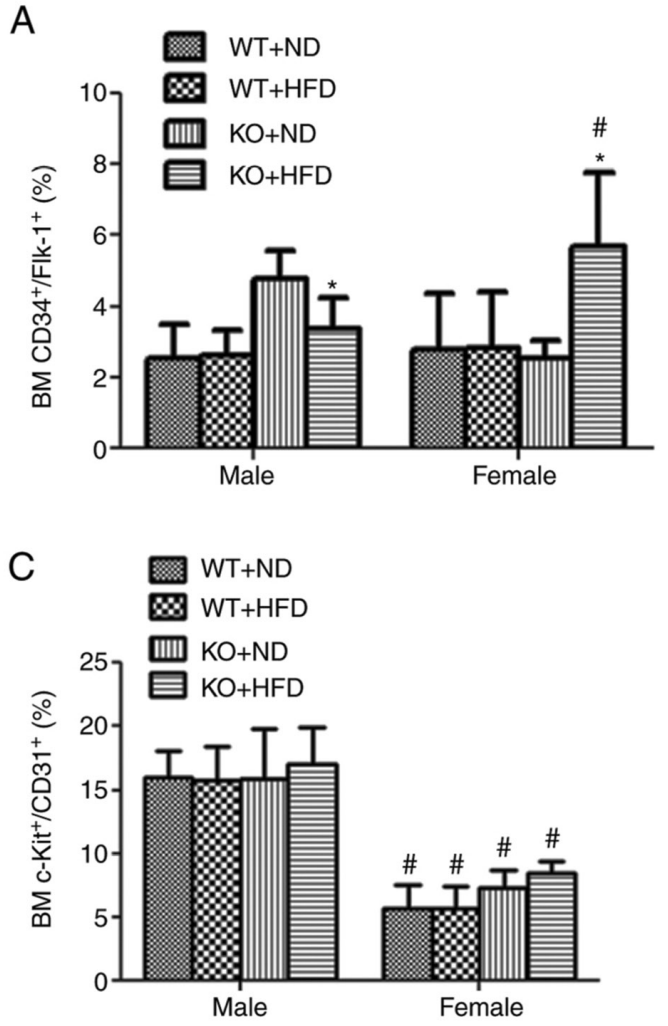

E

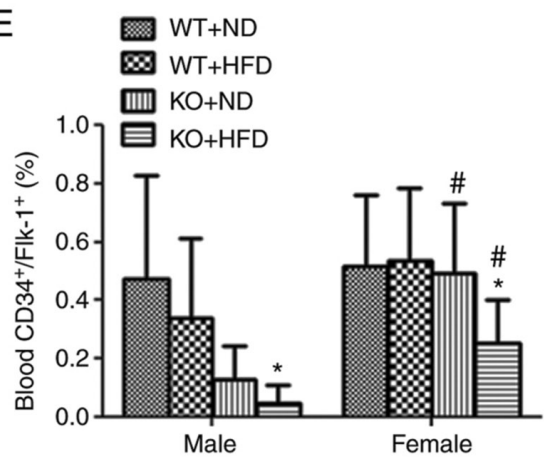

G

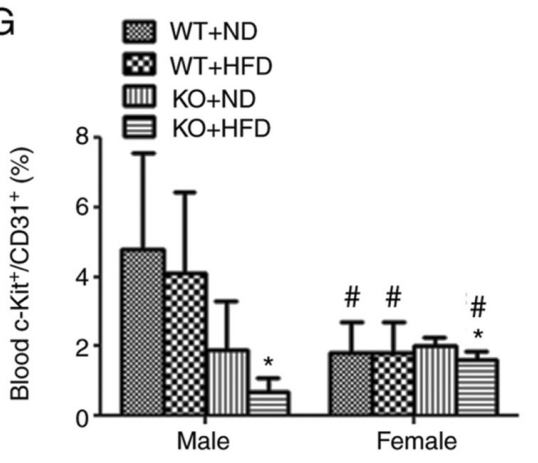

B

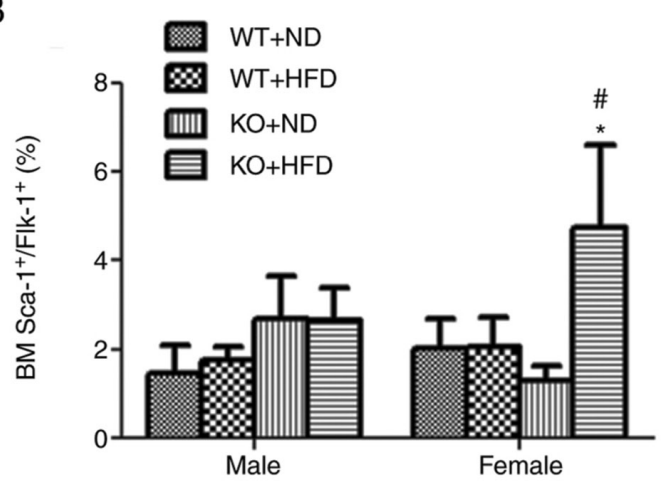

D

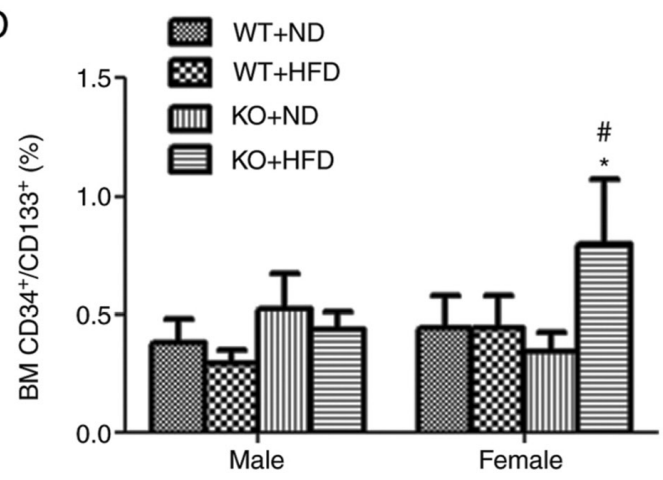

F

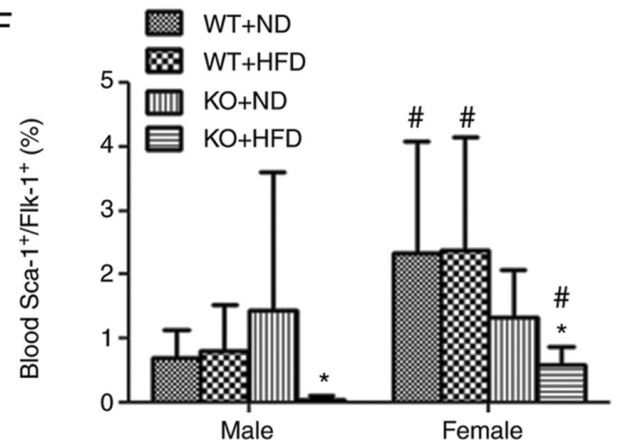

$\mathrm{H}$

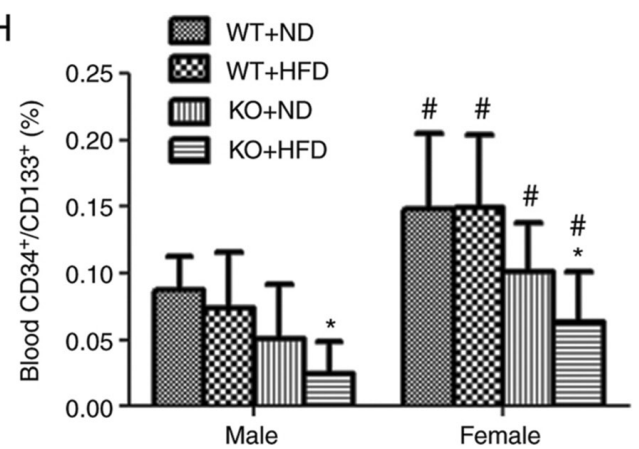

Figure 2. Sustained high level of murine BM and circulating EPCs in female hyperlipidemic mice. After 6 months of feeding with a HFD, the peripheral blood cells and BM were harvested, and the red blood cell were eliminated for flow cytometry analysis. (A-H) Populations of the cells expressing CD34 ${ }^{+} / \mathrm{Flk}-1^{+}$, or $\mathrm{Sca}-1^{+} / \mathrm{Flk}-1$, or $\mathrm{c}-\mathrm{Kit}^{+} / \mathrm{CD} 31^{+}$or $\mathrm{CD} 34^{+} / \mathrm{CD} 133^{+}$in both $\mathrm{BM}$ and blood were analyzed. The murine BM and circulating EPCs were maintained at a higher level in female hyperlipidemic mice compared with the males. ${ }^{*} \mathrm{P}<0.05$ vs. KO+ND; ${ }^{\#} \mathrm{P}<0.05$ vs. the respective male group. BM, bone-marrow; EPC, endothelial progenitor cell; HFD, high-fat diet; ND, normal diet; Flk-1, fetal liver kinase-1; Sca-1, stem cell antigen-1; LDLR ${ }^{-/}$, low density lipoprotein receptor knock out; WT+ND, WT C57BL/6 mouse with ND for 6 months; WT+HFD, WT C57BL/6 mouse with HFD for 6 months; KO+ND, LDLR ${ }^{-/}$mice with ND for 6 months; $\mathrm{KO}+\mathrm{HFD}, \mathrm{LDLR}^{-/-}$mice with HFD for 6 months.

found to be significantly increased in both female and male LDLR $^{-1-}$ mice compared with those in the LDLR ${ }^{-/}$mice fed a ND (P<0.05; Fig. 4A and B). Of note, the TNF- $\alpha$ and IL-6 levels in all HFD-fed female LDLR ${ }^{-/}$mice were significantly lower compared with those in the male $\mathrm{LDLR}^{-/-}$mice fed a HFD (P<0.05; Fig. 4A and B). 

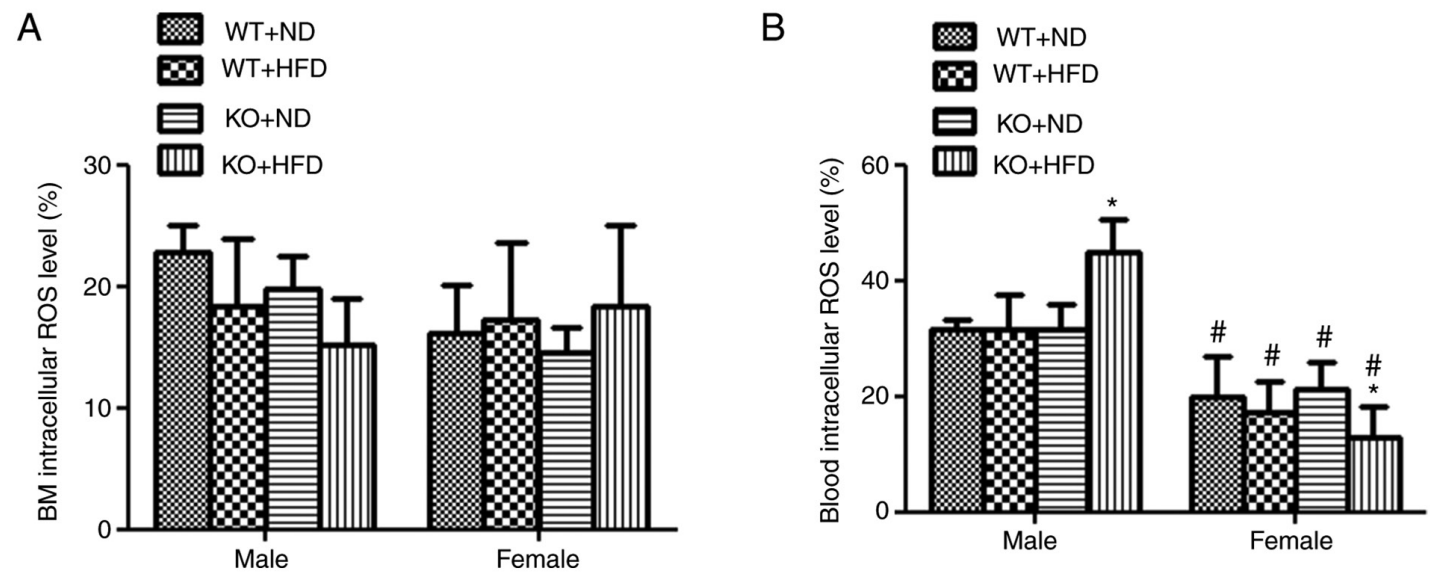

Figure 3. Decreased levels of intracellular ROS formation in blood EPCs in female hyperlipidemic mice. (A) There were no changes in intracellular ROS formation in the BM in all groups of mice. (B) Intracellular ROS production is significantly increased in the blood EPCs in the male hyperlipidemic LDLR ${ }^{-1}$ mice, whereas it decreased or was not changed in the female mice. ${ }^{*} \mathrm{P}<0.01 \mathrm{vs.} \mathrm{KO}+\mathrm{ND}$; ${ }^{\prime} \mathrm{P}<0.01$ vs. the respective male group. EPC, endothelial progenitor cell; ROS, reactive oxygen species; BM, bone marrow; ND, normal diet; LDLR ${ }^{-/}$, low density lipoprotein receptor knock out; WT+ND, WT C57BL/6 mouse with ND for 6 months; WT+HFD, WT C57BL/6 mouse with HFD for 6 months; KO+ND, LDLR ${ }^{-/}$mice with ND for 6 months; KO+HFD, LDLR ${ }^{-/-}$mice with HFD for 6 months.
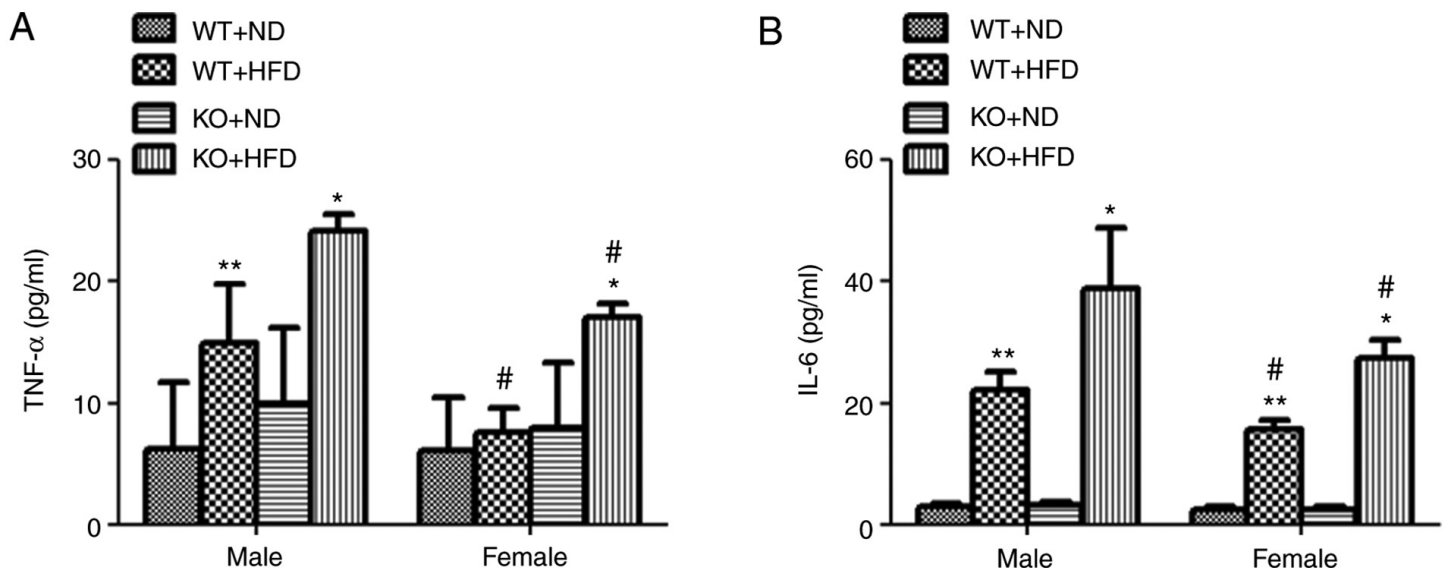

Figure 4. Low levels of proinflammatory cytokine secretion in female hyperlipidemic mice. There was a significant increase in (A) TNF- $\alpha$ and (B) IL-6 in male and female KO and male WT mice fed a HFD compared with the ND control group. However, the total levels of TNF- $\alpha$ and IL- 6 in male mice were considerably higher than that in the female mice after HFD feeding. ${ }^{*} \mathrm{P}<0.01,{ }^{* *} \mathrm{P}<0.01 \mathrm{vs}$. KO+ND; ${ }^{\#} \mathrm{P}<0.01$ vs. the respective male group. LDLR ${ }^{-/}$, low density lipoprotein receptor knock out; WT+ND, WT C57BL/6 mouse with ND for 6 months; WT+HFD, WT C57BL/6 mouse with HFD for 6 months; KO+ND, LDLR $^{-/}$mice with ND for 6 months; KO+HFD, LDLR ${ }^{-/}$mice with a high fat diet for 6 months.

High numbers of BM and circulating EPCs coupled with low levels of intracellular ROS are observed in female mice following ox-LDL treatment. Ox-LDL treatment was used as the primary hyperlipidemic mediator to treat both male and female WT mice for 3 days prior to measuring their EPC numbers and intracellular ROS levels. In ox-LDL-treated male mice, the BM CD34 $4^{+} / \mathrm{Flk}-1^{+}$, c-Kit ${ }^{+} / \mathrm{CD} 31^{+}$(Fig. 5A and C) and circulating Sca- $1^{+} / \mathrm{Flk}-1^{+}$and $\mathrm{c}-\mathrm{Kit}^{+} / \mathrm{CD} 31^{+}$(Fig. $5 \mathrm{~F}$ and G) cell populations were significantly decreased $(\mathrm{P}<0.05)$ compared with mice without ox-LDL treatment. However, $\mathrm{BM}$ and circulating $\mathrm{CD} 34^{+} / \mathrm{CD} 133^{+}($Fig. 5D and $\mathrm{H})$ and circulating $\mathrm{CD}_{34}{ }^{+} / \mathrm{Flk}-1^{+}$cell numbers (Fig. 5E) were significantly increased $(\mathrm{P}<0.05)$. There was little to no change in the entire EPC population (Fig. 5A, B and D-H), except for the fact that the $\mathrm{BM} \mathrm{c}-\mathrm{Kit}^{+} / \mathrm{CD} 31^{+}$population (Fig. 5C) was significantly increased $(\mathrm{P}<0.05)$ in female mice following ox-LDL treatment compared with female mice without ox-LDL treatment (Fig. 5). The female BM and circulating CD $34^{+} / \mathrm{Flk}^{+} 1^{+}$(Fig. $5 \mathrm{~A}$ and E), CD $34^{+} / \mathrm{CD} 133^{+}$ (Fig. 5D and $\mathrm{H}$ ) and $\mathrm{BM} \mathrm{c-Kit} / \mathrm{CD} 31^{+}($Fig. $5 \mathrm{C})$ populations were significantly increased $(\mathrm{P}<0.05)$ compared with those in male mice treated with ox-LDL.

Subsequently, the BM and blood EPC intracellular ROS levels were measured. Similar to that in the hyperlipidemic mice, there were no changes in ROS levels in the BM in both male and female mice with or without ox-LDL treatment (Fig. 6A). However, the intracellular blood ROS levels were significantly elevated in ox-LDL-treated male mice $(\mathrm{P}<0.01)$ compared with that in the ox-LDL-treated female mice (Fig. 6B).

\section{Discussion}

The present study demonstrated that the plasma lipid levels and atherosclerotic plaque formation were notably reduced in female hyperlipidemic mice. The BM and circulating EPCs 

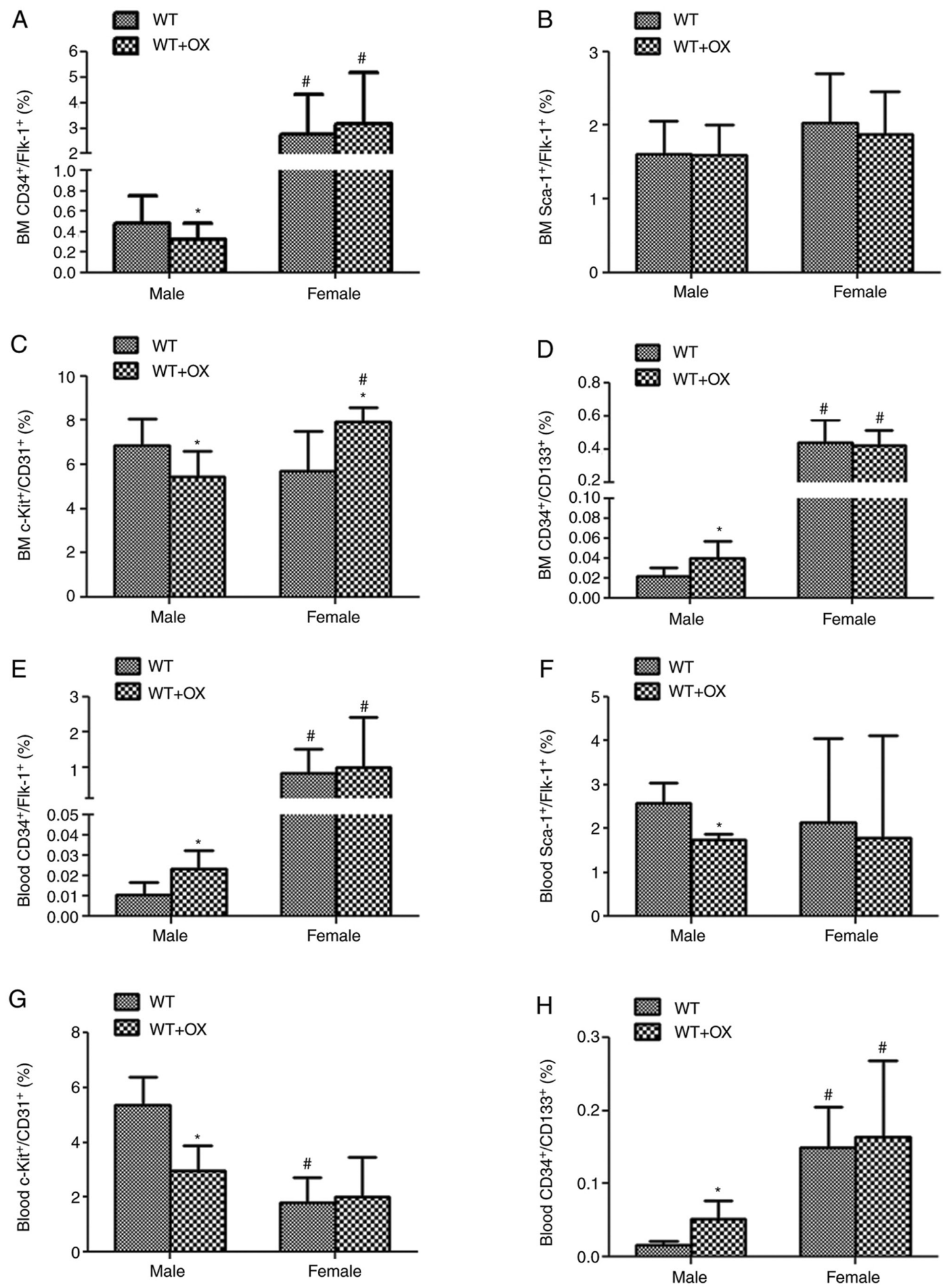

Figure 5. Sustained high levels of murine BM and circulating EPCs in female WT mice following ox-LDL treatment. (A-H) After 3 days of ox-LDL injection, the BM and peripheral blood cells were collected, and the red blood cells were eliminated for flow cytometry analysis. The EPC populations in both BM and blood were analyzed as shown. Following ox-LDL treatment, the murine BM and circulating EPCs were maintained at a higher level in female mice compared with the male mice. ${ }^{*} \mathrm{P}<0.05$ vs. WT+OX; ${ }^{\#} \mathrm{P}<0.05$ vs. the respective male group. ox-LDL, oxidized low-density lipoprotein; BM, bone marrow; EPC, epithelial progenitor cell.

were maintained in higher numbers in female mice with hyperlipidemia and following ox-LDL treatment. The potential mechanisms may be associated with lower levels of intracellular blood EPC ROS formation, and native LDL, plasma IL-6 and TNF- $\alpha$ levels in female mice compared with those in their male counterparts. To the best of our knowledge, the present study was the first to investigate the effect of differences in sex on the reaction to hyperlipidemia and ox-LDL in different subgroups of EPCs in the BM and blood.

Ox-LDL is an important mediator of hyperlipidemia that is closely associated with a number of cardiovascular diseases (1-3). Ox-LDL interrupts the activity of EPCs 
A
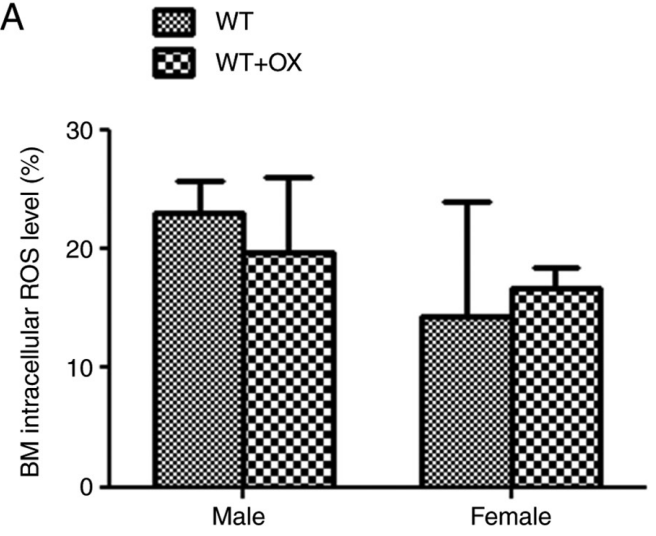

B
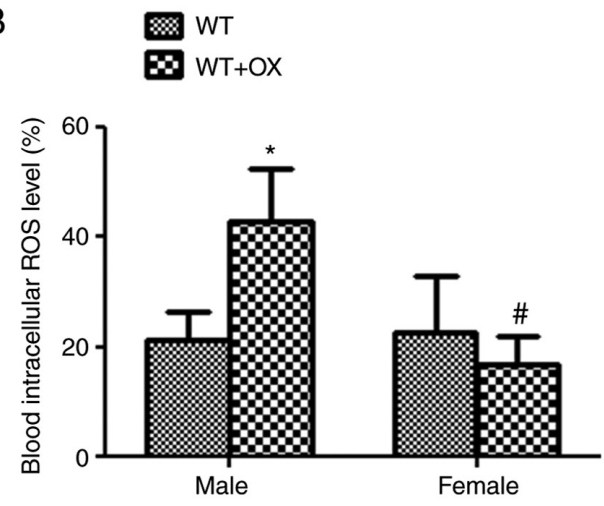

Figure 6. Intracellular ROS formation in blood EPCs in male mice is increased following ox-LDL treatment. (A) No changes in the intracellular ROS formation were observed in the BM in all groups of mice. (B) Intracellular ROS production is significantly increased in the blood EPCs in the male mice following ox-LDL treatment, while there were no changes in the female mice. ${ }^{~} \mathrm{P}<0.01$ vs. WT+OX; ${ }^{~} \mathrm{P}<0.01$ vs. respective male group. EPC, endothelial progenitor cell; $\mathrm{BM}$, bone marrow; ROS, reactive oxygen species; ox-LDL, oxidized low-density lipoprotein.

through various mechanisms, including the downregulation of E-selectin and integrin $\alpha(v) \beta$ (5) expression, suppression of endothelial nitric oxide synthase, acceleration of cell senescence, suppressing telomerase, promotion of ROS generation and proinflammatory factor secretion in cardiovascular diseases, possibly due to the cardioprotective effects of estrogen (1). It has been reported that estrogen can inhibit EPC apoptosis and senescence, whilst promoting EPC mobilization (40). In addition, greater migratory activity and colony-forming capacity in vitro are also exhibited by EPCs isolated from middle-aged women compared with those isolated from men, which provides further support of the protective effects of endogenous estrogen on EPC function (41). In the present study, almost all groups of BM and blood EPCs were maintained at higher numbers in female mice with hyperlipidemia or following ox-LDL treatment compared with their male counterparts. Apart from the direct effects on EPC, estrogen may also provide a beneficial environment for EPCs, including suppression of pro-atherogenic gene expression, induction of atheroprotective gene expression, downregulation of IL-6 expression (42), generation of protective growth factors, including vascular endothelial growth factor and insulin-like growth factor $1(43,44)$, in addition to the upregulation of suppressor proteins of cytokine signaling, resulting in resistance to the effects of deleterious TNF- $\alpha$ signaling in women $(45,46)$. In support of these previous findings, the present study also demonstrated that native plasma LDL, IL- 6 and TNF- $\alpha$ levels were considerably lower in female mice compared with those in males.

Although androgen receptors are expressed by EPCs, there is only limited evidence showing the effects of androgens on EPCs. Fadini et al (47) suggested that there is no correlation between androgen stimulation and late EPC expansion and adhesion in vitro after isolating both early and late human EPCs. Nevertheless, the number of circulating EPCs decreased after castration, and this reduction was irreversible, even with exogenous testosterone administration (47). In a previous clinical study of healthy middle-aged men, circulating EPCs were shown to exhibit a closer correlation with estrogen compared with testosterone (48). The growth-stimulatory and pro-survival effects of testosterone may be limited to mature progenitor cells (48). In addition, analysis of plasma steroid levels in patients with irritable bowel syndrome found that EPCs were not correlated with testosterone levels (49). Therefore, testosterone may well be less influential than estrogen on EPC physiology, although conflicting evidence exists concerning the effects of androgens in this context.

The formation of ROS and the resulting oxidative stress are important mechanisms underlying the effects of ox-LDL (7). ROS can disrupt normal EPC function and is related to a variety of diseases, including CAD, diabetes, hyperlipidemia and renal ischemia-reperfusion injury $(8-10,15)$. It has been reported that the extent of oxidative stress was higher in males than females in rats (17), human serum (18) and human vascular cells (19). In addition, both previous experimental and clinical studies suggested a potentially more powerful antioxidant capacity in females over males (20). The present study suggested a correlation between sex differences and the levels of oxidative stress, where females are less prone to ROS damage. A previous study on mice suggested that the stronger antioxidant protection from ROS in females may be related to the higher levels of pulmonary and brain superoxide dismutase (SOD) activity (50). Additionally, it has been demonstrated that estradiol can activate the MAP kinase signaling pathway, to upregulate manganese-SOD gene expression (51). Another study reported that estrogen can act as an antioxidant scavenger to eliminate free radicals due to the presence of the phenolic hydroxyl group (17). ROS levels were also shown to be higher in spayed female rats compared with corresponding female controls, but no significant difference was found in male rats after castration (17). By contrast, differences in the expression of NADPH-oxidase subunits were also observed between the two sexes, with higher expression of Nox1 and Nox4 in males compared with that in females (52). The higher expression of Nox1 and Nox4 in men could partially explain why males are more susceptible to oxidative stress than females. The present study showed that intracellular blood EPC ROS formation was reduced in female mice with hyperlipidemia or after ox-LDL treatment compared with that in their male counterparts. 
There remain a number of questions on the mechanisms underlying the effects of hyperlipidemia or ox-LDL on EPCs in different sexes that need to be addressed. It is well-established that the identification and characterization of EPCs is a challenging and complex process as shown in previous studies (53-57). There are no uniform criteria for the identification of EPCs as of yet. However, combinations of a variety of cell markers are frequently used to characterize EPCs in the literature. Specifically, CD $34^{+} / \mathrm{Flk}-1^{+}, \mathrm{Sca}-1^{+} / \mathrm{Flk}-1^{+}$, $\mathrm{c}-\mathrm{Kit}^{+} / \mathrm{CD} 31^{+}$and the $\mathrm{CD} 34^{+} / \mathrm{CD} 133^{+}$cell populations are primarily distributed in the blood and $\mathrm{BM}$, and confer protective effects on the cardiovascular system (58-61). To provide a broader picture on the sex-specific reaction of EPCs under conditions of hyperlipidemia or after ox-LDL treatment, the specific EPC population responsible for the protective effects against atherosclerosis must be investigated in a future study. In addition, other potential mechanisms mediating the high numbers of BM and circulating EPCs in female mice warrants further study. The effect of estrogen on the modulation of blood lipid levels and estrogen receptors on EPCs upstream of plaque formation is a line of research worthy of further investigation. Furthermore, the application of these findings in clinical studies and the respective outcomes would be the ultimate desired outcomes of research into this field.

In conclusion, the present study demonstrated that the decreased atherosclerotic plaque formation in female mice with hyperlipidemia compared with male mice may be due to the sustained high numbers of BM and circulating EPCs in association with lower levels of intracellular blood EPC ROS formation, plasma TNF- $\alpha$ and IL-6 levels, and plasma native LDL levels in female mice compared with those in male mice.

\section{Acknowledgements}

Not applicable.

\section{Funding}

This work was supported by The National Nature Science Foundation of China (grant nos. 81600222 and 81800255), Young experts of Taishan Scholar Program of Shandong Province (grant no. tsqn201812142), Academic Promotion Programme of Shandong First Medical University (grant nos. 2019RC017), The Natural Science Foundation of Shandong Province (grant nos. ZR2016HM22 and ZR2018BH002) and Clinical Medical Science and Technology Innovation Development Plan Project of Jinan in China (grant nos. 201704106).

\section{Availability of data and materials}

The datasets used and/or analyzed during the present study are available from the corresponding author on reasonable request.

\section{Authors' contributions}

YC and LC designed the experiments. XZ, HB, YJ, XM, LY, ST, QZ, YX and YC performed the experiments. ZS, KH, LC,
PZ and HS collected and analyzed the data. YC and ST wrote the manuscript. All authors have read and approved the final manuscript. YC, HS, XZ and HB confirm the authenticity of all the raw data.

\section{Ethics approval and consent to participate}

All human procedures were performed in accordance with the Guidelines of the Human Research Ethics Committee of the Shandong Second Provincial General Hospital Affiliated to Shandong University (Jinan, China). The Human Research Ethics Committee of the Shandong Second Provincial General Hospital Affiliated to Shandong University (Jinan, China) approved the experimental protocols (approval no. XYK20181224). All participants agreed to use their samples for scientific research, and informed consent was obtained. All animal procedures were performed in accordance with the Guidelines of the Animal Care Committee of the Shandong Second Provincial General Hospital Affiliated to Shandong University (Jinan, China). The Animal Care Committee of Shandong Second Provincial General Hospital Affiliated to Shandong University approved the experimental protocols (approval no. XYK20181225).

\section{Patient consent for publication}

Not applicable.

\section{Competing interests}

The authors declare that they have no competing interests.

\section{References}

1. Guo Y, Yin F, Fan C and Wang Z: Gender difference in clinical outcomes of the patients with coronary artery disease after percutaneous coronary intervention: A systematic review and meta-analysis. Medicine (Baltimore) 97: el1644, 2018.

2. Shufelt CL, Pacheco C, Tweet MS and Miller VM: Sex-specific physiology and cardiovascular disease. Adv Exp Med Biol 1065: 433-454, 2018

3. Woodward M: Cardiovascular disease and the female disadvantage. Int J Environ Res Public Health 16: 1165, 2019.

4. Mudyanadzo TA: Endothelial progenitor cells and cardiovascular correlates. Cureus 10: e3342, 2018.

5. Kattoor AJ, Kanuri SH and Mehta JL: Role of Ox-LDL and LOX-1 in atherogenesis. Curr Med Chem 26: 1693-1700, 2019.

6. Hartley A, Haskard D and Khamis R: Oxidized LDL and anti-oxidized LDL antibodies in atherosclerosis-Novel insights and future directions in diagnosis and therapy. Trends Cardiovasc Med 29: 22-26, 2019.

7. Cui Y, Narasimhulu CA, Liu L, Zhang Q, Liu PZ, Li X, Xiao Y, Zhang J, Hao H, Xie X, et al: $\mathrm{N}$-acetylcysteine inhibits in vivo oxidation of native low-density lipoprotein. Sci Rep 5: 16339, 2015.

8. Hamed S, Brenner B and Roguin A: Nitric oxide: A key factor behind the dysfunctionality of endothelial progenitor cells in diabetes mellitus type-2. Cardiovasc Res 91: 9-15, 2011.

9. Thum T and Bauersachs J: Spotlight on endothelial progenitor cell inhibitors: Short review. Vasc Med 10 (Suppl 1): S59-S64, 2005.

10. Zhang Q, Chen L, Si Z, Bu H, Narasimhulu CA, Song X, Cui MY, Liu H, Lu T, He G, et al: Probucol protects endothelial progenitor cells against oxidized low-density lipoprotein via suppression of reactive oxygen species formation in vivo. Cell Physiol Biochem 39: 89-101, 2016.

11. Cui Y, Narasimhulu CA, Liu L, Li X, Xiao Y, Zhang J, Xie X, Hao H, Liu JZ, He G, et al: Oxidized low-density lipoprotein alters endothelial progenitor cell populations. Front Biosci (Landmark Ed) 20: 975-988, 2015. 
12. Hermsdorff HH, Barbosa KB, Volp AC, Puchau B, Bressan J, Zulet MÁ and Martínez JA: Gender-specific relationships between plasma oxidized low-density lipoprotein cholesterol, total antioxidant capacity, and central adiposity indicators. Eur J Prev Cardiol 21: 884-891, 2014.

13. Lemieux C, Cloutier I and Tanguay JF: Menstrual cycle influences endothelial progenitor cell regulation: A link to gender differences in vascular protection? Int J Cardiol 136: 200-210, 2009.

14. Fadini GP, de Kreutzenberg S, Albiero M, Coracina A, Pagnin E, Baesso I, Cignarella A, Bolego C, Plebani M, Nardelli GB, et al: Gender differences in endothelial progenitor cells and cardiovascular risk profile: The role of female estrogens. Arterioscler Thromb Vasc Biol 28: 997-1004, 2008.

15. Forrester SJ, Kikuchi DS, Hernandes MS, Xu Q and Griendling KK: Reactive oxygen species in metabolic and inflammatory signaling. Circ Res 122: 877-902, 2018.

16. Botham KM and Wheeler-Jones CP: Postprandial lipoprotein and the molecular regulation of vascular homeostasis. Prog Lipid Res 52: 446-464, 2013.

17. Barp J, Araujo AS, Fernandes TR, Rigatto KV, Llesuy S, Belló-Klein A and Singal P: Myocardial antioxidant and oxidative stress changes due to sex hormones. Braz J Med Biol Res 35: $1075-1081,2002$

18. Ide T, Tsutsui H, Ohashi N, Hayashidani S, Suematsu N, Tsuchihashi M, Tamai $\mathrm{H}$ and Takeshita A: Greater oxidative stress in healthy young men compared with premenopausal women. Arterioscl Throm Vas 22: 438-442, 2002

19. Matarrese P, Colasanti T, Ascione B, Margutti P, Franconi F, Alessandri C, Conti F, Riccieri V, Rosano G, Ortona E and Malorni W: Gender disparity in susceptibility to oxidative stress and apoptosis induced by autoantibodies specific to RLIP76 in vascular cells. Antioxid Redox Signal 15: 2825-2836, 2011.

20. Kander MC, Cui Y and Liu Z: Gender difference in oxidative stress: A new look at the mechanisms for cardiovascular diseases. J Cell Mol Med 21: 1024-1032, 2017.

21. Ji KT, Chai JD, Xing C, Nan JL, Yang PL and Tang JF: Danshen protects endothelial progenitor cells from oxidized low-density lipoprotein induced impairment. J Zhejiang Univ Sci B 11: 618-626, 2010

22. Santee SM and OwenSchaub LB: Human tumor necrosis factor receptor $\mathrm{p} 75 / 80(\mathrm{CD} 120 \mathrm{~b})$ gene structure and promoter characterization. J Biol Chem 271: 21151-21159, 1996.

23. Ali ES, Mangold C and Peiris AN: Estriol: Emerging clinical benefits. Menopause 24: 1081-1085, 2017.

24. Administration CFaD: Food and Drug Administration regulations, 2021 (In Chinese). http://www.nhc.gov.cn/wjw/s9492/202 004/31b4fa14ee174bb1999142525ceba608/files/fd630f2e64cd40 60aae826e07d00f562.pdf.

25. Chung BH, Wilkinson T, Geer JC and Segrest JP: Preparative and quantitative isolation of plasma lipoproteins: Rapid, single discontinuous density gradient ultracentrifugation in a vertical rotor. J Lipid Res 21: 284-291, 1980.

26. Chandrakala AN, Sukul D, Selvarajan K, Sai-Sudhakar C, Sun B and Parthasarathy S: Induction of brain natriuretic peptide and monocyte chemotactic protein-1 gene expression by oxidized low-density lipoprotein: Relevance to ischemic heart failure. Am J Physiol Cell Physiol 302: C165-C177, 2012.

27. Li X, Jiang M, Tan T, Narasimhulu CA, Xiao Y, Hao H, Cui Y, Zhang J, Liu L, Yang C, et al: N-acetylcysteine prevents oxidized low-density lipoprotein-induced reduction of MG53 and enhances MG53 protective effect on bone marrow stem cells. J Cell Mol Med 24: 886-898, 2020.

28. Chang PC, Wu HL, Lin HC, Wang KC and Shi GY: Human plasminogen kringle 1-5 reduces atherosclerosis and neointima formation in mice by suppressing the inflammatory signaling pathway. J Thromb Haemost 8: 194-201, 2010.

29. Cui Y, Liu L, Xiao Y, Li X, Zhang J, Xie X, Tian J, Sen CK, He X, Hao H and Liu Z: N-acetylcysteine differentially regulates the populations of bone marrow and circulating endothelial progenitor cells in mice with limb ischemia. Eur J Pharmacol 881: 173233, 2020.

30. Traverse JH, Henry TD, Pepine CJ, Willerson JT, Zhao DX, Ellis SG, Forder JR, Anderson RD, Hatzopoulos AK, Penn MS, et al: Effect of the use and timing of bone marrow mononuclear cell delivery on left ventricular function after acute myocardial infarction: The TIME randomized trial. JAMA 308 , 2380-2389, 2012

31. Perin EC, Willerson JT, Pepine CJ, Henry TD, Ellis SG, Zhao DX, Silva GV, Lai D, Thomas JD, Kronenberg MW, et al: Effect of transendocardial delivery of autologous bone marrow mononuclear cells on functional capacity, left ventricular function, and perfusion in chronic heart failure: The FOCUS-CCTRN Trial. JAMA 307: 1717-1726, 2012.
32. Zhao Y, Yu P, Wu R, Ge Y, Wu J, Zhu J and Jia R: Renal cell carcinoma-adjacent tissues enhance mobilization and recruitment of endothelial progenitor cells to promote the invasion of the neoplasm. Biomed Pharmacother 67: 643-649, 2013.

33. Yang JJ, Ii M, Kamei N, Alev C, Kwon SM, Kawamoto A, Akimaru H, Masuda H, Sawa Y and Asahara T: CD34+ Cells represent highly functional endothelial progenitor cells in murine bone marrow. PLoS One 6: e20219, 2011.

34. Liu LP, Kakiuchi-Kiyota S, Arnold LL, Johansson SL, Wert D and Cohen SM: Pathogenesis of human hemangiosarcomas and hemangiomas. Hum Pathol 44: 2302-2311, 2013.

35. Feng YM, Schouteden S, Geenens R, Van Duppen V, Herijgers P, Holvoet P, Van Veldhoven PP and Verfaillie CM: Hematopoietic Stem/Progenitor cell proliferation and differentiation is differentially regulated by high-density and low-density lipoproteins in mice. PLoS One 7: e47286, 2012.

36. Westerweel PE, Teraa M, Rafii S, Jaspers JE, White IA, Hooper AT, Doevendans PA and Verhaar MC: Impaired endothelial progenitor cell mobilization and dysfunctional bone marrow stroma in diabetes mellitus. PLoS One 8: e60357, 2013.

37. Houlihan DD, Mabuchi Y, Morikawa S, Niibe K, Araki D, Suzuki S, Okano $\mathrm{H}$ and Matsuzaki Y: Isolation of mouse mesenchymal stem cells on the basis of expression of Sca-1 and PDGFR- $\alpha$. Nat Protoc 7: 2103-2111, 2012

38. Bilski P, Belanger AG and Chignell CF: Photosensitized oxidation of 2',7'-dichlorofluorescin: Singlet oxygen does not contribute to the formation of fluorescent oxidation product 2',7'-dichlorofluorescein. Free Radical Bio Med 33: 938-946, 2002.

39. Robinson JP, Bruner LH, Bassoe CF, Hudson JL, Ward PA and Phan SH: Measurement of intracellular fluorescence of human-monocytes relative to oxidative-metabolism. J Leukocyte Biol 43: 304-310, 1988.

40. Cai JJ, Wen J, Jiang WH, Lin J, Hong Y and Zhu YS: Androgen actions on endothelium functions and cardiovascular diseases. J Geriatr Cardiol 13: 183-196, 2016.

41. Hoetzer GL, MacEneaney OJ, Irmiger HM, Keith R, Van Guilder GP, Stauffer BL and DeSouza CA: Gender differences in circulating endothelial progenitor cell colony-forming capacity and migratory activity in middle-aged adults. Am J Cardiol 99: 46-48, 2007.

42. Liu H, Liu K and Bodenner DL: Estrogen receptor inhibits interleukin-6 gene expression by disruption of nuclear factor kappaB transactivation. Cytokine 31: 251-257, 2005.

43. Hamada H, Kim MK, Iwakura A, Ii M, Thorne T, Qin G, Asai J, Tsutsumi Y, Sekiguchi H, Silver M, et al: Estrogen receptors alpha and beta mediate contribution of bone marrow-derived endothelial progenitor cells to functional recovery after myocardial infarction. Circulation 114: 2261-2270, 2006.

44. Shao R, Egecioglu E, Weijdegård B, Kopchick JJ, Fernandez-Rodriguez J, Andersson N and Billig H: Dynamic regulation of estrogen receptor-alpha isoform expression in the mouse fallopian tube: Mechanistic insight into estrogen-dependent production and secretion of insulin-like growth factors. Am J Physiol Endocrinol Metab 293: E1430-E1442, 2007.

45. Matthews J, Almlof T, Kietz S, Leers J and Gustafsson JA: Estrogen receptor-alpha regulates SOCS-3 expression in human breast cancer cells. Biochem Biophys Res Commun 335: 168-174, 2005.

46. Roggia C, Gao YH, Cenci S, Weitzmann MN, Toraldo G, Isaia $\mathrm{G}$ and Pacifici R: Up-regulation of TNF-producing T cells in the bone marrow: A key mechanism by which estrogen deficiency induces bone loss in vivo. Proc Natl Acad Sci USA 98: 13960-13965, 2001.

47. Fadini GP, Albiero M, Cignarella A, Bolego C, Pinna C, Boscaro E, Pagnin E, De Toni R, de Kreutzenberg S, Agostini C and Avogaro A: Effects of androgens on endothelial progenitor cells in vitro and in vivo. Clin Sci (Lond) 117: 355-364, 2009.

48. Kim SW, Hwang JH, Cheon JM, Park NS, Park SE, Park SJ, Yun HJ, Kim S and Jo DY: Direct and indirect effects of androgens on survival of hematopoietic progenitor cells in vitro. J Korean Med Sci 20: 409-416, 2005.

49. Garolla A, D'Inca R, Checchin D, Biagioli A, De Toni L, Nicoletti V, Scarpa M, Bolzonello E, Sturniolo GC and Foresta C: Reduced endothelial progenitor cell number and function in inflammatory bowel disease: A possible link to the pathogenesis. Am J Gastroenterol 104: 2500-2507, 2009.

50. Chen Y, Ji LL, Liu TY and Wang ZT: Evaluation of gender-related differences in various oxidative stress enzymes in mice. Chinese J Physiol 54: 385-390, 2011.

51. Vina J, Gambini J, Lopez-Grueso R, Abdelaziz KM, Jove M and Borras C: Females live longer than males: Role of oxidative stress. Curr Pharm Design 17: 3959-3965, 2011 
52. Miller AA, Drummond GR, Mast AE, Schmidt HH and Sobey CG: Effect of gender on NADPH-oxidase activity, expression, and function in the cerebral circulation: Role of estrogen. Stroke 38: 2142-2149, 2007.

53. Leal V, Ribeiro CF, Oliveiros B, Antonio N and Silva S: Intrinsic vascular repair by endothelial progenitor cells in acute coronary syndromes: An Update overview. Stem Cell Rev 15: 35-47, 2019.

54. Zaccone V, Flore R, Santoro L, De Matteis G, Giupponi B, Li Puma DD and Santoliquido A: Focus on biological identity of endothelial progenitors cells. Eur Rev Med Pharmacol Sci 19 4047-4063, 2015.

55. Kawakami Y, Matsumoto T, Mifune Y, Fukui T, Patel KG, Walker GN, Kurosaka M and Kuroda R: Therapeutic potential of endothelial progenitor cells in the field of orthopaedics. Curr Stem Cell Res Ther 12: 3-13, 2017.

56. Testa U, Saulle E, Castelli G and Pelosi E: Endothelial progenitor cells in hematologic malignancies. Stem Cell Investig 3: 26, 2016.

57. Sandhu K, Mamas M and Butler R: Endothelial progenitor cells: Exploring the pleiotropic effects of statins. World J Cardiol 9: $1-13,2017$
58. Kawamoto A and Asahara T: Role of progenitor endothelial cells in cardiovascular disease and upcoming therapies. Catheter Cardiovasc Interv 70: 477-484, 2007.

59. Torsney E and Xu Q: Resident vascular progenitor cells. J Mol Cell Cardiol 50: 304-311, 2011.

60. Heissig B, Werb Z, Rafii S and Hattori K: Role of c-kit/Kit ligand signaling in regulating vasculogenesis. Thromb Haemost 90: 570-576, 2003

61. Beneventi F, De Maggio I, Cavagnoli C, Bellingeri C, Ruspini B, Riceputi G, Viarengo G, Ramoni V and Spinillo A: Endothelial progenitor cell $\mathrm{CD} 34^{+}$and $\mathrm{CD} 133^{+}$concentrations and soluble HLA-G concentrations during pregnancy and in cord blood in undifferentiated connective tissue diseases compared to controls. Reprod Sci 28: 1382-1389, 2021.

This work is licensed under a Creative Commons Attribution-NonCommercial-NoDerivatives 4.0 International (CC BY-NC-ND 4.0) License. 